\title{
Pumping of Fresh Concrete: Insights and Challenges
}

\author{
Geert De Schutter ${ }^{a^{*}}$, Dimitri Feys ${ }^{b}$ \\ ${ }^{a}$ Magnel Laboratory for Concrete Research, Department of Structural Engineering, Ghent University, Belgium \\ ${ }^{b}$ Department of Civil, Architectural and Environmental Engineering, Missouri University of Science and Technology, MO, United States
}

Received: 22 September 2016 / Accepted: 10 November 2016 / Published online: 25 November 2016

(C) The Author(s) 2016. This article is published with open access.

\begin{abstract}
Pumping of fresh concrete is of utmost importance for concrete practice. Required pumping pressures are typically estimated based on design charts. However, with the increased use of chemical admixtures and the development of more flowable concrete mixtures, the accuracy of traditional design charts is questioned. In recent years, significant progress has been obtained in understanding the flow of the material in the pumping pipe, including the behavior of the lubrication layer near the pipe surface. In comparison with traditional design charts, this results in more reliable pressure predictions when considering very fluid concrete types like self-consolidating concrete. Some remaining challenges can be defined however.
\end{abstract}

Keywords: Pumping; Concrete; Rheology; Lubrication layer; Pressure

\section{Introduction}

Although the Romans mastered concrete construction in an amazing way (considering the scientific and technological knowledge in that era), we now have about a century of experience of working with modern concrete construction. However, new developments in powder and admixture technology have given a boost to the materials science of cementitious materials only in the past two decades. Modern concrete is a high-tech material, which is a remarkable example of applied nanotechnology that combines many disciplines like chemistry, physics, and mechanics. The excellent rheological properties of modern fresh cementitious materials have not been sufficiently translated into new production opportunities. Local traditions often prevail over new scientific concepts and technologies, and current production processes do not take full profit of the rheological potential of new developments in cementitious materials. Encountered problems are manifold, and include high pumping pressures, leaking of formworks, and excessive formwork pressures. This letter focuses on pumping of fresh concrete, showing shortcomings with traditional approaches, and challenges for further improvement.

\section{Traditional approach to predict pumping pressure}

Pumping is a practical and efficient method to place concrete inside a formwork. For nearly a century, concrete pumps and pipes, and guidelines to design pumpable concrete are continuously improved. However, these improvements are mostly based on trial and error approaches and are largely supported by experiences in the field. Similarly, predicting pumping pressure is based on practical design charts, developed from experiential observations [1-3]. These design charts allow users to determine the pressure needed to pump concrete based on the desired flow rate, the diameter of the used pipes, the equivalent length of the pipeline (suggesting amplification factors for bends and reducers), and a fresh concrete property. Dependent on the origin of the chart, this fresh concrete property is either the slump [3] or the spread [1].

These charts were successfully employed in the last decades of the previous century, but with the increased use of chemical admixtures and the development of more flowable concrete mixtures, a modification is required. Flowable mixtures have large slump or spread values, and according to the practical charts, pumping pressure should be really low. However, practical experience indicates that flowable mixtures, including self-consolidating concrete (SCC) may even require more pressure to be pumped, compared to a conventional vibrated concrete (CVC) [4-5]. Furthermore, in

\footnotetext{
* Corresponding author: Geert De Schutter, geert.deschutter@ugent.be
} 
fluid mechanics, pressure is related to the viscosity of the fluid, not its yield stress, slump or spread [6-8]. In fact, at the time of the development of the practical charts, the concrete slump was mostly varied by adding water, modifying paste volume or changing the aggregate grain size distribution. Most of these variations have an influence on yield stress and viscosity at the same time, hence justifying why the slump or spread value of the concrete was a good indicator [9]. However, nowadays, with more complex dispersing agents and viscosity-enhancing admixtures, yield stress and viscosity can be fine-tuned separately, necessitating the introduction of viscosity into the pumping charts.

\section{Physical background}

\subsection{What kind of material is concrete?}

In order to enable the theoretical study of the flow or deformation of a material, it needs to be classified. As concrete is a complex mixture of air, water and a lot of solids, this classification is not straightforward. Concrete can be considered as a concentrated suspension of solids in water, or it can be considered as a soil-like material where inter-particle contact is dominating [10]. In fact, for concrete, both classifications are valid and mainly depend on the relative quantity of coarse aggregates in the mixture [10]. If a lot of coarse aggregates are present, their inter-particle friction is dominating the deformation behavior. In this case, concrete behaves as a soil, and based on Coulomb's principle: any stress to deform the sample is proportional to the applied normal stress. In the other case, concrete can be regarded as a suspension, and the principles of fluid mechanics and rheology can be applied $[8,11]$.

Browne and Bamforth [12] made a similar distinction in their paper, referring to concrete as saturated (a suspension) or unsaturated (a soil). In case the concrete is saturated, the pressure loss for flow does not depend on the local pressure. In case of unsaturated concrete, the pressure loss does depend on the local pressure (Coulomb's law). Browne and Bamforth mathematically proved that pumping saturated concrete is much more advantageous [12]. Unsaturated concrete has significantly more chance to result in blockage.

In fact, the practical guidelines for designing pumpable concrete are based on this principle to avoid friction, by reducing the coarse aggregate size, volume and increasing sand and cement-paste content [1, 3, 12-13]. Also blocking during start-up, in which a plug of coarse aggregates is formed in front of the concrete, is based on the friction principle [12, 14-15]. If the concrete transitions from a suspension into a soil-like material in a small section of the pipes, it may block the entire line.

\subsection{Flow regime}

Assuming concrete is a suspension, to predict pumping pressure, it is essential to know in which regime concrete is flowing: laminar, turbulent or in transition [7]. The flow regime will determine whether the pressure loss is linearly dependent on the flow rate (laminar), or approximately related to the flow rate squared (turbulent). Simplifying concrete as a Newtonian liquid, neglecting the yield stress, the Reynolds number (Re) can be calculated as follows:

$\operatorname{Re}=\frac{\rho V D}{\mu}$

The density $(\rho)$ of concrete is usually around $2500 \mathrm{~kg} / \mathrm{m}^{3}$. Choosing a large diameter $(D)$ of $0.2 \mathrm{~m}$, and a high flow rate of $40 \mathrm{l} / \mathrm{s}\left( \pm 140 \mathrm{~m}^{3} / \mathrm{h}\right)$, results in an average velocity $(V)$ equal to $1.25 \mathrm{~m} / \mathrm{s}$. Selecting a low viscosity $(\mu)$ for the concrete: e.g. $10 \mathrm{~Pa} \cdot \mathrm{s}$, leads to a Reynolds number of $\mathrm{Re}=62.5$. Knowing that laminar flow occurs for Reynolds numbers below 2100 , concrete flow in pipes is fully laminar.

\subsection{Prediction of pressure in laminar flow}

In circular pipes, regardless of the used fluid, the shear stress distribution is linear, increasing from zero in the center to the maximum value at the wall $\left(=R \Delta p_{\text {tot }} / 2 L\right.$, with $R=$ radius). Knowing the shear stress distribution, the shear rate can be calculated if the rheological properties are known, and from the shear rate evolution with the pipe radius, the velocity profile and flow rate can be determined, assuming adherence conditions (no slip) at the interface [78]. For Newtonian fluids, the Poiseuille equation enables the prediction of the total pressure $\left(\Delta p_{\text {tot }}\right)$ based on the flow rate $(Q)$ in laminar flow, or vice-versa [6-7].

$Q=\frac{\pi \Delta p_{t o t} D^{4}}{128 \mu L}$

Increasing viscosity or increasing the length $(L)$ of the pipeline results in a proportional increase in pressure loss to keep the flow rate constant. Decreasing the diameter requires an increase of the pressure to the power 4 at constant flow rate.

For Bingham materials, the yield stress $\left(\tau_{0}\right)$ plays an additional role on the pressure loss - flow rate relationship. Following a similar analytical derivation as for the Newtonian case, the Buckingham-Reiner equation is obtained [16]:

$Q=\pi \frac{3 \Delta p_{t o t}{ }^{4} R^{4}+16 \tau_{0}{ }^{4} L^{4}-8 \tau_{0} L R^{3} \Delta p_{t o t}{ }^{3}}{24 \Delta p_{\text {tot }}{ }^{3} \mu L}$

From the Buckingham-Reiner equation, it can be seen that both the yield stress and the plastic viscosity influence the pressure loss - flow rate relationship. In fact, the effect of the yield stress is never decoupled from the viscosity (both the second and third terms are related to $\tau_{0} / \mu$ ), but the effect of the viscosity is decoupled from the yield stress (first term). The presence of the yield stress causes a part of the Bingham material to flow as a plug, thus at uniform velocity, in pipes. The magnitude of this plug zone depends on the yield stress and on the pressure losses (which are influenced by $\tau_{0}, \mu, Q$ and $R$ ). The plug zone will always occur in the center of the pipe, as the shear stress, which is related to the pressure loss, evolves linearly from zero in the center to the maximum value at the wall of the pipe.

The effect of the yield stress on pressure loss is important if $\tau_{0} / \mu$ is high. This occurs when the yield stress is elevated and the viscosity is low, which is typical for CVC. However, $\tau_{0} / \mu$ is very low for SCC and the viscosity is the dominating factor for the $\Delta p-Q$ curve. Furthermore, it has been found that 
shear rates in the bulk concrete in pipe lines may be an order of magnitude larger than in a typical concrete rheometer [45]. As SCC has typically higher viscosity compared to CVC, higher pressures may be required to pump SCC, even if the SCC shows lower flow resistance in the rheometer. This is in contradiction with the practical charts, and a modification to incorporate viscosity in these charts is required.

It has also been discovered that when the concrete obeys a non-linear rheological model (this can occur for specific SCC mixtures), the pressure loss - flow rate curve will reflect this model $[4-5,17]$. As a result, if concrete shows shearthickening behavior, special care must be exerted for the mixtures, as pressure losses may be under-estimated when assuming a linear rheological model instead.

Using the Buckingham-Reiner equation, or any extension for non-linear rheological models, has led to a significant overestimation of the pressure loss at a certain flow rate when trying to predict concrete pumping pressure $[4,14,18]$. Typically, the calculated pressure loss is 2 to 5 times, and in some cases 10 times, higher than experimentally measured pressure losses. The reason for this discrepancy can be found in the conditions to apply the Poiseuille equation: the material must remain homogeneous during flow.

\section{$4 \quad$ Lubrication layer formation}

While pumping, the fresh concrete does not remain homogenous, due to the formation of a lubrication layer near the pipe wall (sometimes also misleadingly called 'slip layer' while no slip between concrete and surface occurs [19-20] provide evidence of negligible flow velocity near the pipe wall). Coarse aggregates move slightly towards the pipe center, with the shear rate gradient over the pipe radius as a driving force [21]. As a consequence, cement paste and a fraction of finer material move towards the pipe wall, forming the lubrication layer. The fundamental nature of this lubrication layer formation process requires thus a slight form of dynamic segregation of the concrete at meso-scale.

By considering the composition and the rheology of the lubrication layer, more accurate estimations can be obtained of the pumping pressures for several types of concrete [20, 22]. Correctly assessing the properties of this layer allows accurate predictions of the pumping pressure - flow rate relationship for conventional concrete and self-consolidating concrete [14, 19]. Recently, the design of a tribometer [14] to assess the lubrication layer has been optimized and this has been validated for conventional and self-consolidating concrete in a full-scale pumping circuit [23-24]. In this context, however, it must be remarked that the term 'tribometer' is not correct, as no tribological or friction behavior is occurring. As in a real pumping pipe, a lubrication layer is formed also in the 'tribometer', showing shear deformation. Real tribometers mimic situations where concrete, under pressure, indeed is sliding against a (rough) surface [25]. This situation, however, is not directly relevant for the pumping behavior of suspensions (although Coulomb friction might be relevant for pumping of granular soil-like materials).

\section{Pressure prediction}

Although fundamental models have been developed to predict pressure loss in straight pipes during pumping, it was hard to relate this with the particle migration within the bulk concrete. A lack of readily deployable experimental techniques that visualize the particle migration processes within pumped concrete could be considered as the cause of this shortcoming. Experimental techniques to describe the expected pumping pressure have gained a lot of attention during the last decade. For example, the sliding pipe rheometer has been developed to simulate pipe flow and actually measures concrete pressure [26]. However in practice, full scale pipe line tests are often considered most reliable. Other testing equipment has been limited to either measuring the rheology of wet-screened mortars, or concrete tribometers that provide information about the lubrication layer. Together with measured rheological properties of the concrete, this information can be used as input for the pump pressure prediction models $[14,20]$. Choi et al. [20] have successfully calculated pumping pressures based on an analytical model, where the lubrication layer is assumed to be the wet-screened mortar and the thickness of this layer is based on velocity profile measurements. With the tribometer approach, no information on the composition and thickness of the layer is available, but the application of the analytical model developed by Kaplan has resulted in a good agreement between experimental and predicted pressure loss (Figure 1) [14, 18, 24]. However, extrapolation of these tests to other types of concretes requires careful considerations. For example, the development of the tribometer in [23] to accommodate more flowable concrete (including SCC) required an additional calculation step in assessing the lubrication layer properties.

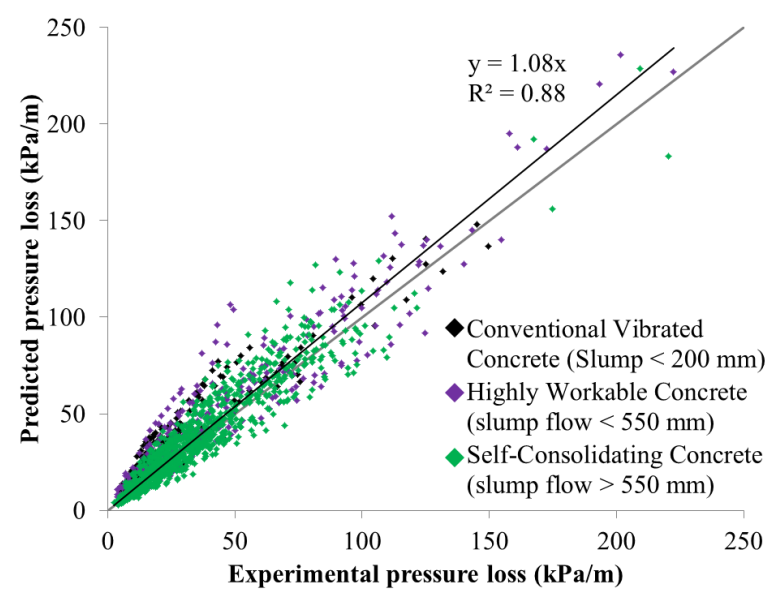

Figure 1. Pumping pressure is well predicted based on Kaplan's model [14], based on tribology and rheology measurements on different types of concrete. Figure modified from [24]. 


\section{Challenges}

\subsection{Formation of lubrication layer in high performance concrete}

At this moment, questions remain concerning the pumping behaviour of specific types of concrete in which the formation of a lubrication layer is not induced, or in which internal friction and Coulomb effects become prevalent, e.g. in case of ultra-high performance concrete (UHPC). UHPC is to a very large extent based on an optimal particle packing of the solid materials, leaving insufficient space to initiate shear-induced particle migration. In ongoing research, it is tried to modify the internal structure of UHPC in order to enable shear-induced particle migration. Another approach in improving the situation (for fresh concrete in general) has been introduced by Choi et al. [27] in a first pilot test, applying an externally imposed electromagnetic field in order to facilitate the formation of a lubrication layer. This technique has been inspired by a recently developed formwork removal technique based on electro-osmosis [28].

\subsection{Test methods for evaluation of pumpability of fresh concrete}

Many test methods have been developed in the past to test pumpability of fresh concrete, mainly to predict whether the concrete will flow through the pipelines or not [12, 14, 29]. Due to the complexity of the phenomena involved: concrete transitioning from flow to friction, coarse aggregates getting ahead of the concrete flow during start-up, pressurized bleeding, etc. [15], none of these tests are actually largely employed on the jobsite. The concrete producers' and operators' experience, and trial and error, are still the current assessment methods for pumpability in the field. In view of pumping UHPC, Eco-concrete with low binder content, mass concrete, etc., in which lubrication formation could be a challenge, a simple test method to predict pumpability, if possible, would be desirable.

\subsection{Bends and reducers}

According to pure hydrodynamics laws, bends and reducers should induce an additional pressure loss, as the streamlines change direction. Practical guidelines for pumping concrete consider a $90^{\circ}$ bend equivalent to $3 \mathrm{~m}$ of straight section [13]. However, Kaplan [14], Chapdelaine [18] and Choi et al. [20] have found no discernable effect of bends on the pressure loss. On the other hand, Feys et al. [4-5], when employing bends with a short radius, have found that in specific situations, the practical guidelines are insufficient to predict the additional pressure loss. The pressure loss in bends (and in reducers) is expected to depend on the rheology of the concrete (or mortar), the bending radius and angle, the coarse aggregate size, content and distribution (as they influence inertia), pipe diameter and flow rate, and any interactions between these properties. Accurately predicting additional pressure losses over bends is thus still a major challenge.

\subsection{Changes in concrete properties due to pumping}

One of the main challenges in concrete pumping is the change in properties induced by the process. As mentioned in sections 3 and 4, the shear rate in the lubrication layer, and in the bulk concrete is in the order of several 10 to $100 \mathrm{~s}$ ${ }^{1}$ [4]. This very high shearing energy can lead to more dispersion of cementitious particles [30-33]. In general, this leads to a decrease in viscosity, induced by the pumping process [33]. For the yield stress though, opposing results are reported in literature. Yield stress can increase, remain constant, or decrease during pumping [33]. For a sensitive concrete mixture, such as SCC, decreasing the yield stress can lead to segregation due to pumping $[5,33]$. The increases in yield stress can compromise the selfconsolidation [5, 33].

A second property which is largely affected by pumping is the air-void system in concrete. From literature, it can be concluded that the air content can increase, decrease or remain constant during pumping [34-37]. Especially a decrease in air content could be detrimental for freeze-thaw durability of air-entrained concrete mixtures, while an increase in entrapped air leads to a decrease in compressive strength. Furthermore, in many cases, an increase in the spacing factor of the air-void system is reported [36-38].

\subsection{Active control}

During current pumping operations, the only option is to control the pumping pressure or the discharge rate while operating the pump. Short interruptions of the pumping process can lead to major difficulties in resuming pumping operations due to the sometimes tremendous effect of internal structural build-up or thixotropy. Current pumping operations do not allow for the active control of the concrete rheology during pumping. Once the concrete enters the pump, the operator can only passively consider the evolution of the rheological properties of the cementitious material, and has no means to adjust the material properties.

Although the electromagnetic field applied by Choi et al. [27] improved the formation of the lubrication layer, they still passively relied on the rheological properties of the pumped concrete. A new challenge, as currently studied in the ERC Advanced Grant Project 'SmartCast' [39] aims to introduce a ground-breaking approach by developing an innovative concrete mix design containing responsive polymer admixtures interacting with applied electromagnetic fields, enabling the active adjustment of the lubrication layer based on real-time in-line flow measurements while pumping.

\section{Conclusions}

Pumping of fresh concrete is of utmost importance for concrete practice. In recent years, significant progress has been obtained in understanding the flow of the material in the pumping pipe, including the behavior of the lubrication layer near the pipe surface. In comparison with traditional 
design charts, this results in more reliable pressure predictions when considering very fluid concrete types like self-consolidating concrete. Some remaining challenges can be defined however.

- Ultra-high performance concrete (UHPC) and similar highly packed granular materials cannot be easily pumped as the lubrication layer is not commonly formed.

- In general, easy and reliable test methods for on-site testing of pumpability of fresh concrete need further development.

- The effect of bends and reducers in pumping lines needs further attention in view of a more reliable quantification of pressure loss.

- The changes in concrete properties due to pumping need to be further investigated in view of more reliable predictions.

- Actively controlling concrete rheology and flow while pumping would make concrete pumping (and formwork casting) safer and more reliable.

Worldwide intensive research actions in this respect will hopefully result in breakthrough solutions within reasonable time.

\section{References}

[1] K. v. Eckardstein, Pumping, Concrete and Concrete Pumps - A Concrete Placing Manual, Schwing, 1983.

[2] R. Crepas, Pumping Concrete, Techniques and Applications, 3rd Edition, Crepas and Associates, Inc., Elmhurst, 1997.

[3] ACl-Committee 304, Placing Concrete by Pumping Methods, American Concrete Institute, Farmington Hills, 1998.

[4] D. Feys, G. De Schutter, R. Verhoeven, Parameters Influencing Pressure during Pumping of Self-Compacting Concrete, Mater Struct (2013) 46: 533-555. https://doi.org/10.1617/s11527-012-9912-4

[5] D. Feys, Interaction between Rheological Properties and Pumping of Self-Compacting Concrete, Ghent: Ghent University, 2009.

[6] J. Poiseuille, Recherches expérimentales sur le mouvement des liquides dans les tubes de très-petits diamèters, CR Acad Sci Paris (1840) 11: 961-967, 1041-1049.

[7] L. Malvern, Introduction to the Mechanics of Continuous Medium, Englewood Cliffs, NJ, Prentice-Hall, Inc., 1969.

[8] C. Macosko, Rheology Principles, Measurements and Applications, New York, VCH, 1994.

[9] O. Wallevik, J. Wallevik, Rheology as a tool in concrete science: The use of rheographs and workability boxes, Cem Concr Res (2011) 41: 1279-1288. https://doi.org/10.1016/i.cemconres.2011.01.009

[10] J. Yammine, M. Chaouche, M. Guerinet, M. Moranville, N. Roussel, From Ordinary Rheology Concrete to Self Compacting Concrete: A Transition between Frictional and Hydrodynamic Interactions, Cem Concr Res (2008) 38: 890-896. https://doi.org/10.1016/j.cemconres.2008.03.011

[11] G. Tattersall, P. Banfill, The rheology of fresh concrete, London: Pitman, 1983.

[12] R. Browne, P. Bamforth, Tests to establish concrete pumpability, ACl-Journal (1977) 74: 193-203.

[13] A. Ede, The resistance of concrete pumped through pipelines," Mag Concr Res (1957) 9: 129-140. https://doi.org/10.1680/macr.1957.9.27.129

[14] D. Kaplan, Pumping of Concretes, PhD thesis (in French), Paris: Laboratoire Central des Ponts et Chaussées, 2001.

[15] D. Kaplan, F. de Larrard, T. Sedran, Avoidance of Blockages in Concrete Pumping Process, ACI Mat J (2005) 102(3): 183-191.

[16] E. Buckingham, On plastic flow through capillary tubes, Proc Am Soc Test Mater (1921) 21: 1154-1161.

[17] D. Feys, R. Verhoeven, G. De Schutter, Extension of the Poiseuille formula for shear thickening materials and application to self compacting concrete, Appl Rheol (2008) 18(6): 62705.
[18] F. Chapdelaine, Fundamental and Practical Study on Pumping of Concrete, PhD thesis (in French), Quebec-City, Université Laval, 2007.

[19] H. Le, Study on the influence of the lubrication layer on velocity profiles during concrete pumping (in French), Cergy-Pontoise: Universite Cergy-Pontoise, Ghent University, 2014.

[20] M. Choi, N. Roussel, Y. Kim, J. Kim, Lubrication layer properties during concrete pumping, Cem Concr Res (2013) 45: 69-78. https://doi.org/10.1016/i.cemconres.2012.11.001

[21] R. Phillips, R. Armstrong, R. Brown, A. Graham, J. Abbott, A Constitutive Equation for Concentrated Suspensions that Accounts for Shear-Induced Particle Migration, Phys Fluids A (1992) 4(1): 30 40. https://doi.org/10.1063/1.858498

[22] M. Choi, Y. Kim, S. Kwon, Prediction of pipe flow of pumped concrete based on shear-induced partilce migration, Cem Concr Res (2013) 52: 216-224. https://doi.org/10.1016/j.cemconres.2013.07.004

[23] D. Feys, K. Khayat, A. Perez-Schell, R. Khatib, Development of a tribometer to characterize lubrication layer properties of selfconsolidating concrete, Cem Concr Comp (2014) 54: 40-52. https://doi.org/10.1016/j.cemconcomp.2014.05.008

[24] D. Feys, K. Khayat, A. Perez-Schell, R. Khatib, Prediction of pumping pressure by means of new tribometer for highly-workable concrete, Cem Conc Comp (2015) 57: 102-115. https://doi.org/10.1016/j.cemconcomp.2014.12.007

[25] Y. Vanhove, C. Djelal, A. Magnin, A device to study fresh concrete friction, Cem Conc Aggr (2004) 26: 35-41. https://doi.org/10.1520/CCA11897

[26] V. Mechtcherine, V. Nerella, K. Kasten, Testing pumpability of concrete using sliding pipe rheometer, Constr Build Mater (2014) 53: 312-323. https://doi.org/10.1016/j.conbuildmat.2013.11.037

[27] M. Choi, Y. Kim, J. Kim, J. Kim, S. Kwon, Effects of an externally imposed magnetic field on the formation of a lubrication layer in concrete, Constr Build Mater (2014) 61: 18-23. https://doi.org/10.1016/j.conbuildmat.2014.02.071

[28] N. Goudjil, Y. Vanhove, C. Djelal, H. Kada, Electro-osmosis applied for formwork removal of concrete, J Adv Concr Techn (2012) 10: 301312. https://doi.org/10.3151/jact.10.301

[29] J. Gray, Laboratory procedure for comparing pumpability of concrete mixtures, in 6th Annual Meeting of the National Crushed Stone Association, 964-971, Washington, DC, 1962.

[30] M. Ouchi, J. Sakue, Self-compactability of fresh concrete in terms of dispersion and coagulation of particles of cement subject to pumping, in Proceedings of the 3rd North-American Conference on the Design and Use of Self-consolidating Concrete, Chicago, IL, 2008.

[31] K. Takahashi, T. Bier, Mechanisms for the changes in fluidity and hydration kinetics of grouts after mixing, in Proc. of the 6th Int. RILEM Conference on Self-Compacting Concrete, Paris, 2013.

[32] K. Takahashi, T. Bier, T. Westphal, Effects of mixing energy on technological properties and hydration kinetics of grouting mortars, Cem Concr Res (2011) 41: 1167-1176. https://doi.org/10.1016/j.cemconres.2011.07.005

[33] D. Feys, G. De Schutter, K. Khayat, R. Verhoeven, Changes in rheology of self-consolidating concrete induced by pumping, Mater Struct (2016) 49(11): 4657-4677. https://doi.org/10.1617/s11527-016-0815-7

[34] K. Hover, Some recent problems with air-entrained concrete, Cem Concr Aggr (1989) 11(1): 67-72. https://doi.org/10.1520/CCA10104J

[35] R. Pleau, M. Pigeon, A. Lamontagne, M. Lessard, Influence of pumping on characteristics of air-void system of high-performance concrete, Transport Res Rec (1995) 1478: 30-36.

[36] K. Hover, R. Phares, Impact of concrete placing method on air content, air-void system parameters, and freeze-thaw durability, Transport Res Rec (1995) 1532: 1-8. https://doi.org/10.3141/1532-01

[37] M. Lessard, M. Baalbaki, P.-C. Aitcin, Effect of pumping on air characteristics of conventional concrete, Transport Res Rec (1995) 1532: 9-14. https://doi.org/10.3141/1532-02

[38] D. Feys, P. Zacarias, S. Van Zetten, L. Keller, B. Schultz, K. Riding, Maintaining the Air-Void System during Pumping of SelfConsolidating Concrete: a Challenging Fluid Mechanics Problem!, in Proc. of the 8th Int. RILEM and the 6th North-American Conference on SCC, Washington, DC, 2016.

[39] G. De Schutter, Smart casting of concrete structures by active control of rheology, Smartcast, ERC Advanced Grant Project, European Research Council, 2016-2021. 